\title{
ANALISA POLA PEMESANAN PRODUK MODERN TRADE INDEPENDENT DENGAN MENEREPAKAN ALGORITMA FP. GROWTH (STUDI KASUS: PT. ADAM DANI LESTARI)
}

\author{
Russy Amelia, Dito Putro Utomo
}

Program Studi Teknik Informatika, STMIK Budi Darma, Medan, Indonesia

Email : russy.amelia58@gmail.com

\begin{abstract}
Abstrak
Pemesanan dalam bidang jual beli diperusahaan Ritail besar maupun kecil biasa terjadi untuk memenuhi kebutuhan toko agar sampai kekonsumen, itu mencakup list barang dan harga dengan item-item yang berbeda-beda serta ukuran beraneka ragam, pemesanan dilakukan dengan melihat stok yg hampir habis atau habis. Karena banyaknya item-item barang yang mengakibatkan pemesanan kurang efisien mengingat setiap toko MTI memesanan barang yang berbeda-beda, maka dianalisa pola pemesananya berdasarkan item yang saling bersamaan saat pengorderannya dengan menerapkan algoritam FP.Growth, untuk memepermudah pemesanan barang yang akan diorder dan efisien. Hasil yang didapat pemesanan secara bersamaan oleh MTI, mempermudah pemesanan dari analisa pola yang telah dilakukan. Hasil yang didapat dari penelitian yaitu item barang rekomendasi yaitu 2 atau lebih item yang disarankan melalui analisa menggunakan algoritma fp.growth dengan confidence (interval kepercayaan diatas $20 \%$ ) dan minimum support 5\%. Tools yang digunakan Rapidminer 9.32019 menghasilkan tabel dan grafik dari algoritma fp.growth dan Association Rule.
\end{abstract}

Kata Kunci: Analisa, Pemesanan Produk Algoritma FP.Growth, RapidMiner 9.3.

\begin{abstract}
Ordering in the field of sale and purchase of Ritail large and small ordinary happens to meet the needs of the store to reach consumers, it includes a list of goods and prices with different items and a variety of sizes, bookings made By looking at low or low stocks. Because the number of items that resulted in the booking is less efficient considering that each MTI store is tracking the different items, it is analyzed the pattern of the order based on the items simultaneously during the order by applying Algorithm. Growth, to easily order goods to be ordered and efficient. The results of the booking are at the same time by MTI, making it easier to order from the pattern analysis. Results obtained from the study of item recommendation is 2 or more items suggested through analysis using FP. Growth algorithm with confidence (confidence interval above 20\%) and minimum 5\% support. The Tools used Rapidminer 9.3 2019 generate tables and graphs from the FP. Growth algorithm and the Association Rule.
\end{abstract}

Keywords: analysis, ordering products FP. Growth, RapidMiner 9.3.

\section{PENDAHULUAN}

Unilever Merupakan perusahan besar yang menjual kebutuhan sehari-hari/pokok yang digunakan masyarakat setiap saat, dimana menjual perlengkapan personal care, skin care, dan home care dan food. PT.Adam Dani Lestari adalah perusahaan yang berada di Medan sebagai Distributor atau pihak ke-2 penyalur barang atau produk Unilever, dimana pihak atau karyawan yang bekerja dibawah naungan perusahaan ini melakukan pengorderan barang atau pemesanan barang diswalayan di sebut chanel MTI (Modern Trade Independent) yaitu market tidak nasional yang ada hanya pada kota tertentu saja, dan PT. Mitra Andal Sejati sebagai pihak ke-3 yang menyalurkan SDM (Sumber Daya Manusia) untuk meningkatkan penjualan produk Unilever dengan cara promosi di toko-toko atau market yang telah di tentukan .

Dalam hal ini pengorderan (pemesanan) produk dilakukan setiap minggunya, chanel MTI (Modern Trade Independent) untuk memenuhi kebutuhan market, setiap mingggunya pemesanan produk selalu berbeda-beda dan tergantung adanya promo yang ditawarkan serta sesuai kebutuhan market masing-masing, produk yang telah diorder di simpan list produknya kedalam sebuah tab yang kemudian datanya akan ditarik oleh admin untuk dikirim kegudang, sesampai digudang data tersebut dicetak menjadi lembaran faktur, setelah barang disediakan sesuai faktur supir mengantar barang ketoko sesuai orderan.

Masalah yang timbul tidak diketahui produk apa saja yang di order berbarengan, agar nantinya produk tidak kehabisan stock atau over stock, Maka dari itu analisa pola pemesanan dilakukan untuk melihat seberapa sering item produk yang paling banyak diorder berbarengan pada chanel MTI (Modern Trade Independent). Untuk mencapai omset penjualan barang maka digunakanlah strategi dengan melihat item-item produk yang paling banyak diorder dan kemudian disupport hadiah atau promo-promo menarik lainnya. Dengan menggunakan algoritma FP.Growth (Frequent Pattern Growth) untuk menentukan produk yang sering dipesan oleh MTI.

\section{TEORITIS}

\subsection{Data Mining}

Menurut Eko Prasetyo pada buku Data Mining Konsep dan Aplikasi Menggunakan Matlab mengatakan "Teknik data mining adalah bagaimana mencari data yang tersedia untuk menciptakan sebuah model, lalu memanfaatkan model tersebut untuk mengenali pola data lain yang tidak tersedia didalam basis data yang tersimpan. Dalam data 
mining pengelompokan data dapat juga dilakukan untuk mengetahui pola secara universal dari data yang tersedia agar dilakukan langkah tindak lanjut lainnya yang berguna sebagai pendukung kegiatan dan tujuan akhir tertentu" [2].

\subsection{Algoritma Frequent Pattern Grwoth (FP-Growth)}

Algoritma FP-Growth merupakan pengembangan dari algoritma Apriori. Algoritma Frequent Pattern Growth (FP-Growth) adalah salah satu alternatif algoritma yang dapat digunakan untuk menentukan himpunan data yang paling sering muncul (frequent itemset) dalam sebuah kumpulan data. Pada algoritma FP-Growth menggunakan konsep pembangunan tree, yang biasa disebut FP-Tree, dalam pencarian frequent itemset bukan menggunakan generate candidate seperti yang dilakukan agar dapat memberikan hasil yang maksimal, tahapan-tahapan tersebut yaitu [1]:

1. Tahap pembangkitan conditional pattern base.

2. Tahap pembangkitan conditional FP- pada algoritma Apriori. Dengan menggunakan konsep tersebut, algoritma FP-Growth menjadi lebih cepat daripada algoritma Apriori. Algoritma FP-Growth memiliki tahapan-tahapan yang harus dilewati Tree.

3. Tahap pencarian frequent itemset.

Association rule merupakan sutu proses pada data mining untuk menentukan semua aturan asosiatif yang memenuhi syarat minimum untuk support (minsup) dan confidance (minconf) pada sebuah database. Kedua syarat tersebut akan digunakan untuk interesting association rules dengan dibandingkaan dengan batasan yang telah ditentukan, yaitu minsup dan minconf.

Association Rule Mining adalah suatu prosedur untuk mencari hubungan antar item dalam suatu dataset. Dimulai dengan mencari frequent itemset, yaitu kombinasi yang paling sering terjadi dalam suatu itemset dan harus memenuhi minsup. Dalam tahap ini akan dilakukan pencarian kombinasi item yang memenuhi syarat minimum dari nilai support dalam database. Untuk mendapatkan nilai support dari suatu item A dapat diperoleh dengan rumus berikut:

$$
\text { Support (A) }=\frac{\text { Jumlah Transaksi Mengandung Item A }}{\text { Total Transaksi }}
$$

Kemudian, untuk mendapatkan nilai support dari dua item diperoleh dengan rumus berikut:

$$
\text { Support }(\mathrm{A}, \mathrm{B})=\mathrm{P}(\mathrm{A} \cap \mathrm{B})=\frac{\text { Jumlah Transaksi Yang Mengandung A dan } B}{\text { Total Transaksi }}
$$

Setelah semua frequent item dan large item set didapatkan, dapat dicari syarat minimum confidence (mincof) dengan menggunakan rumus berikut :

\subsection{Rapid Miner}

$$
\text { Confidence }(\mathrm{A} \rightarrow \mathrm{B})=\mathrm{P}(\mathrm{A} \mid \mathrm{B})=\frac{\text { Jumlah Transaksi Yang Mengandung A dan } B}{\text { Jumlah Transaksi Yang Mengandung } A}
$$

Rapid Miner merupakan perangakat lunak yang bersifat terbuka (open source). Rapid Miner adalah sebuah solusi untuk melakukan analisis terhadap data mining, text mining dan analisis pengelompokan [6]. Rapid Miner menggunakan berbagai teknik deskriptif dan prediksi dalam memberikan wawasan kepada pengguna sehingga dapat membuat keputusan yang paling baik. Rapid Miner memiliki kurang lebih 500 operator data mining, termasuk operator untuk input, output, data preprocessing dan visualisasi. Rapid Miner merupakan software yang berdiri sendiri untuk analisis data dan sebagai mesin data mining yang dapat diintegrasikan pada produknya sendiri. Rapid Miner ditulis dengan munggunakan bahasa java sehingga dapat bekerja di semua sistem operasi.

Rapid Miner menyediakan GUI (Graphic UserInterface) untuk merancang sebuah pipeline analitis. GUI ini akan menghasilkan file XML (Extensible MarkupLanguage) yang mendefenisikan proses analitis keinginan pengguna untuk diterpkan ke data. File ini kemudian dibaca oleh Rapid Miner untuk menjalankan analis secara otomatis.

\section{ANALISA DAN PEMBAHASAN}

\subsection{Analisa Masalah}

Pada penelitian ini penulis menggunakan metode yang akan dijadikan dalam penyelesaian masalah analisis data mining dalam proses pengorderan yang nantinya digunakan untuk mengetahui suatu strategi item produk yang disorder bersamaan, pada bab ini akan membahas analisa proses dengan menggunakan Freqent pattern growth (Fp Growth) yaitu penyelesaian berupa pencarian association rule mining. PT. Adam Dani Lestari dalam proses pengorderan barang masih mengalami kesulitan untuk memperoleh hasil orderan yang optimal karena setiap tokonya memesan item produk yang berbeda-beda, maka dari itu untuk mempermudah proses pengorderan dilakukan analisa pola pemesanan berdasarkan item apa saja yg terkait bila membeli suatu item tertentu untuk hasil pengorderan yang optimal dan mudah.

Maka digunakanlah Analisa pola dengan menngunakan metode FP.Growth dengan pengumpulan data-data pemesanan oleh MTI terdahulu yaitu 4 tahun yang lalu, yaitu mencakup nama item, harga, qty, disc item, dan total harga item yang diambil data selama 3 bulan secara acak. Proses pengorderan nantinya pada PT. Adam Dani Lestari. FP.Growth mempermudah pemesanan karena menganalisa pola-pola pengorderan yang kemudian dapat merekomendasikan pada toko, item-item yang saling bersamaan saat diorder. 


\subsection{Pembahasan}

Data merupakan bagian yang sangat penting dalam Data Mining data yang diambil untuk memnentukan pola pemesanan, Penelitian dilakukan di PT. Adam Dani lestari dengan mengambil data Pemesanan pada tahun 2015, berikut adalah contoh penerapan metode FP.Growth pada data yang peneliti dapatkan. Berdasarkan variabel-variabel yang sudah dipilih dari data pemesanan format data dapat dilihat pada Tabel 1.

Tabel 1. Daftar pemesanan setiap item

\begin{tabular}{lc}
\hline \multicolumn{1}{c}{ Nama Barang } & Kategori \\
\hline Rinso molto cair pch 800ml (RM01) & Fab clean \\
Rinso molto ultra 800gr (RM02) & Fab clean \\
Molto all in one blue 250ml ref (MIO015) & Fab cond \\
Molto trika ref 400ml ble lma (MT013) & Fab cond \\
Pond's am day cream jar 25ml (PDC001) & Face \\
Pond's am night cream bru 10gr (PNC002) & Face \\
Pond's ff acne clear white 100L (PFC003) & Face \\
Pond's ff pure white 100g (PFW004) & Face \\
Pond's wb milk 150 ml (PWB005) & Face \\
Pond's wb toner 150 ml (PWT006) & Face \\
Lifebouy 80gr total procetc (LB90) & Skin cleansing \\
Lifebouy bw 100ml btl white (LB100) & Skin cleansing \\
Lifebouy bw 450ml ref white (LB0101) & Skin cleansing \\
Lifebouy shp 170ml hairfall (LFS11) & Hair \\
Dove cond total hair tretm 160ml (DCH01) & Hair \\
Dove shp daily shine 160ml (DSD002) & Hair \\
Zwitsal b bath 100ml (ZB99) & Baby \\
Zwitsal b cream zinc 100ml (ZB98) & Baby \\
Zwitsal b shampoo 100m alo vera (ZB97) & Baby \\
Zwitsal hair lot 100ml aloe vera (ZB96) & Baby \\
Zwitsal powder 300g fresh flower (ZB95) & Baby \\
Wipol ref 450ml clasik pine (WP5) & HHC \\
Wipol ref 780ml clasik pine (WP6) & HHC \\
Vixal 500ml biru (VX500) & HHC \\
Vixal 800ml biru (VX800) & \\
Kecap bango btl 135ml (BG35) & \\
\hline
\end{tabular}

Setelah itu data input berupa data masukan ketika pemesanan berikut adalah data input yang digunakan untuk proses Data Mining dalam bentuk Tabel item pemesanan, sebagai berikut; Tabel 2. Daftar pemesanan setiap Item

Tabel 2. Daftar pemesanan setiap Item

\begin{tabular}{|c|c|c|}
\hline NO. & Transaksi ID & ITEM SET \\
\hline 1 & $01 \mathrm{~A}$ & RM01 RM02 MIO015 MT013 \\
\hline 2 & 02A & PDC001 DCH01 DSD002 LB0101 \\
\hline 3 & 03A & ZB99 $\quad$ ZB97 $\quad$ ZB96 $\quad$ ZB95 \\
\hline 4 & 04A & LB100 LB0101 LFS11 BG35 \\
\hline 5 & $05 \mathrm{~A}$ & PFW004 PWB005 PWT006 \\
\hline 6 & 06A & VX500 VX800 WP5 WP6 \\
\hline 7 & 07A & PFC003 PFW004 PWB005 \\
\hline 8 & 08A & ZB98 ZB99 DSD002 PDC001 \\
\hline 9 & 09A & LB0101 LB90 LFS11 PFW004 \\
\hline 10 & $010 \mathrm{~A}$ & RM01 RM02 MT013 \\
\hline 11 & $011 \mathrm{~A}$ & DCH01 DSD002 PDC001 PNC002 \\
\hline 12 & $012 \mathrm{~A}$ & WP6 WP5 VX800 \\
\hline 13 & $013 \mathrm{~A}$ & BG35 MIO015 LB0101 ZB99 \\
\hline 14 & $014 \mathrm{~A}$ & ZB98 ZB97 LB90 ZB99 \\
\hline
\end{tabular}




\begin{tabular}{|c|c|c|}
\hline 15 & $015 \mathrm{~A}$ & LB90 DCH01 DSD002 RM02 \\
\hline 16 & 016A & LB90 LB0101 LFS11 PWT006 \\
\hline 17 & 017A & RM02 MIO015 MT013 \\
\hline 18 & 018A & WP5 WP6 VX500 VX800 BG35 \\
\hline 19 & 019A & PNC002 PFC003 PWB005 PWT006 \\
\hline 20 & 020A & LB90 LFS11 MIO015 \\
\hline 21 & $021 \mathrm{~A}$ & LB90 PWT006 PWB005 \\
\hline 22 & $022 \mathrm{~A}$ & ZB99 ZB97 ZB95 \\
\hline 23 & $023 \mathrm{~A}$ & BG35 LB0101 PFW004 PDC001 \\
\hline 24 & 024A & LB90 LB100 LFS11 \\
\hline 25 & $025 \mathrm{~A}$ & MT013 MIO015 RM01 \\
\hline 26 & 026A & LB100 LFS11 LB90 PFC003 \\
\hline
\end{tabular}

Hasil dari proses penelusuran data diketahui jumlah frekuensi kemunculan tiap item yang ada dalam data pemesanan dan mengurutkannya berdasarkan jumlah frekuensi kemunculan item yang paling terbesar.

Tabel 3.Frekuensi kemunculan pada setiap item

\begin{tabular}{lc}
\hline \multicolumn{1}{c}{ Item } & Frekuensi \\
\hline LB90 & 8 \\
LB0101 & 6 \\
LFS11 & 6 \\
MIO015 & 5 \\
RM02 & 4 \\
MT013 & 4 \\
PDC001 & 4 \\
PFW004 & 4 \\
PWB005 & 4 \\
PWT006 & 4 \\
DSD002 & 4 \\
ZB99 & 4 \\
BG35 & 4 \\
RM01 & 3 \\
PFC003 & 3 \\
LB100 & 3 \\
DCH01 & 3 \\
ZB97 & 3 \\
WP5 & 3 \\
WP6 & 3 \\
VX800 & 3 \\
PNC002 & 2 \\
ZB98 & 2 \\
ZB95 & 2 \\
VX500 & 2 \\
ZB96 & 1 \\
\hline
\end{tabular}

Proses pembentukan 1 itemset dengan jumlah minimum support $\geq 15 \%$ dengan rumus sebagai berikut :

Support $(\mathrm{A})=\frac{\text { Jumlah transaksi mengandung } A}{\text { total transaksi }}$

Dari proses perhitungan nilai minimum support dan diambil dengan nilai minimum support $>=15 \%$ sehingga didapatkan data seperti tabel di bawah ini

\begin{tabular}{lcc}
\multicolumn{3}{l}{ Tabel 4. Item yang memenuhi } \\
\hline Item & Frekuensi & Support \\
\hline LB90 & 8 & $31 \%$ \\
LB0101 & 6 & $23 \%$ \\
LFS11 & 6 & $23 \%$ \\
MIO015 & 5 & $19 \%$ \\
RM02 & 4 & $15 \%$ \\
\multicolumn{4}{c}{ Dan seterusnya } \\
\hline
\end{tabular}

Dari proses pembentukan itemset pada Tabel 4.7 dengan minimum support $\geq 15 \%$ dapat diketahui yang memenuhi standar minimum support adalah LB90, LB0101, LFS11, MIO015, RM02, MT013, PDC001, PFW004, 
PWB005, PWT006, DSD002, ZB99, BG35. Tabel berikut mendata kemunculan item yang frequent dalam setiap pemesanan, diurutkan berdasarkan frequentnya paling tinggi.

Tabel 5. Tabel Data pemesanan mengandung minimum Support.

\begin{tabular}{|c|c|}
\hline NO. & ITEM SET \\
\hline $01 \mathrm{~A}$ & MIO015 RM02 MT013 \\
\hline 02A & PDC001 DSD002 LB0101 \\
\hline 03A & ZB99 \\
\hline 04A & LB0101 LFS11 BG35 \\
\hline $05 \mathrm{~A}$ & PFW004 PWB005 PWT006 \\
\hline & Dan seterusnya \\
\hline
\end{tabular}

Sebelum membuat FP-Tree terlebih dahulu membuat TID (Transaksi_ID) setiap item dapat dilihat pada Tabel berikut:

Tabel 6. TID (Transaksi_ID)

\begin{tabular}{rclll}
\hline TID & Transaksi ID & ITEM SET & \\
\hline 1 & $01 \mathrm{~A}$ & RM02 & MIO015 & MT013 \\
2 & 02A & PDC001 & DSD002 & LB0101 \\
3 & 03A & ZB99 & & \\
4 & $04 \mathrm{~A}$ & LB0101 & LFS11 & BG35 \\
5 & 05A & PFW004 PWB005 & PWT006 \\
& & & Dan seterusnya \\
\hline
\end{tabular}

Setelah item-item frequent didapat yang memenuhi nilai support count maka pembangkitan FP Tree dapat dilakukan data akan diolah secara manual sesuai dengan konsep data mining dengan menggunakan algoritma frequent pattern growth (FP Growth). Setelah data diurut dapat kita lanjut pada tahap pembangkitan FP Tree. Pembacaan TID 1 atau transaksi pertama, lalu dilanjutkan pembacaan TID 2 (transaksi kedua), dan dilanjutkan transaksi selaanjutnya hingga transaksi terakhir. Dengan menggunakan frequent pattern growth maka dapat dilanjutkan dengan proses pembangkit FP Tree dari data transaksi yang digunakan. Pada transaksi pertama atau Pembacaaan TID 1 menghasilkan suatu simpul sehingga akan terbentuk suatu lintasan Root dalam pembentukan FP Tree sehingga dapat dilihat dari gambar di bawah ini:

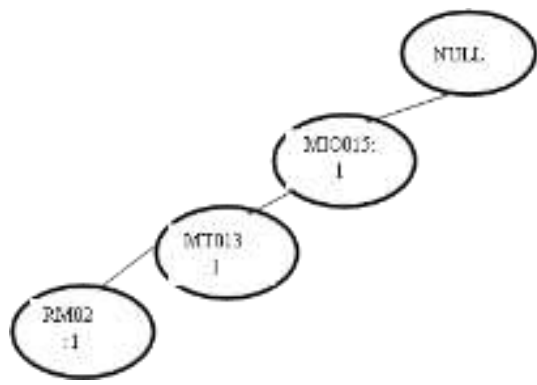

Gambar 1. pembentukan FP-Tree setelah pembacaan TID 1

Pada transaksi kedua atau Pembacaaan TID 2 menghasilkan suatu simpul sehingga akan terbentuk suatu lintasan Root dalam pembentukan FP Tree sehingga dapat dilihat dari gambar di bawah ini:

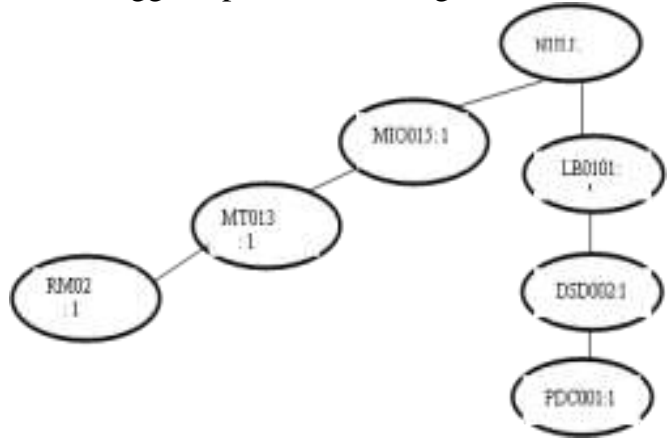

Gambar 2. pembentukan FP-Tree setelah pembacaan TID 2

Pada transaksi keduapuluh empat atau Pembacaaan TID 24 menghasilkan suatu simpul sehingga akan terbentuk suatu lintasan Root dalam pembentukan FP Tree sehingga dapat dilihat dari gambar di bawah ini: 


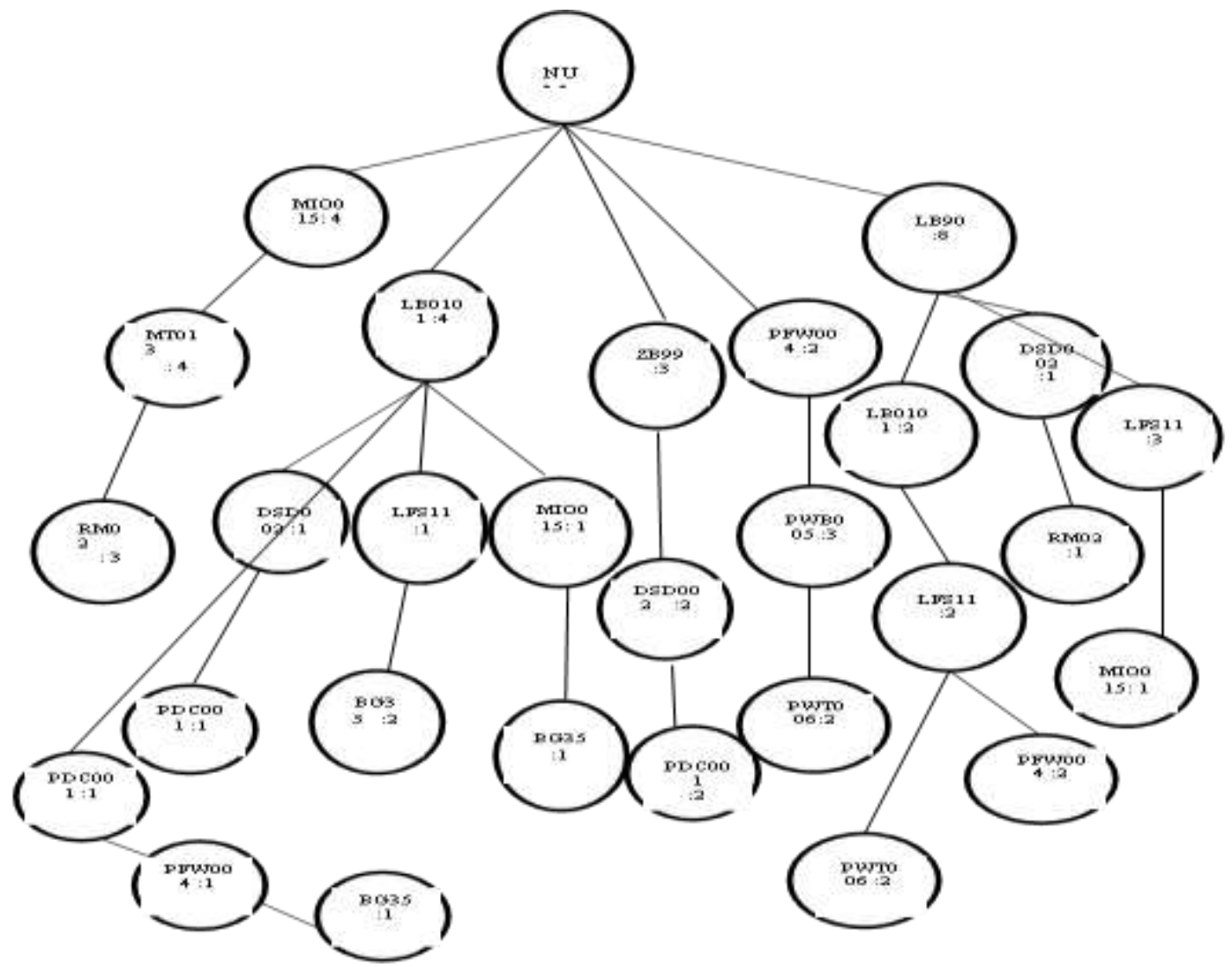

Gambar 3. pembentukan FP-Tree setelah pembacaan TID 24

Berikut ini adalah daftar frequent itemset yang didapatkan untuk pembuatan aturan asosiasi yang dipakai adalah frequent itemset.

\begin{tabular}{lc} 
& Tabel 7. Frequent Itemset \\
\hline Item & Frequent itemset \\
LFS11 & $\{$ LB0101, LFS11 $: 2\}\{$ LB90,LFS11 $: 1\}$ \\
MIO015 & $\{$ LB0101, MIO015:1\} $\{$ LFS11, MIO015:1\} \\
RM02 & $\{$ MT013, RM02:1\} $\{$ DSD002:RM02:1\} \\
MT013 & $\{$ MIO015, MT013:1\} \\
PDC001 & $\{$ LB101, PDC001 $: 1\}\{$ DSD002, PDC001 :1\} \\
PFW004 & $\{$ PDC001, PFW004 :1\} $\{$ LSF11, PFW004:1\} \\
\hline
\end{tabular}

Berdasarkan 10 frequent itemset yang telah terbentuk diatas, semua akan dihitung dalam proses selanjutnya karena memenuhi syarat frequent itemset dalam menghasilkan association rule yaitu minimal memiliki 2 item dimana jika membuka kategori A maka akan membuka kategori B. adapun untuk membentuk subsetnya adalah sebagai berikut :

Tabel 8. Subset

\begin{tabular}{ll}
\hline Suffix & Subset \\
\hline LFS11 & $\{$ LB0101, LFS11:2\} \\
& $\{$ LFS11, LB0101:2\} \\
& $\{$ LB90, LFS11:1\} \\
& $\{$ LFS11, LB90:1\} \\
& $\{$ MIO015, LBO0101:1\} \\
MIO015 & $\{$ LFS11, MIO015:1\} \\
& $\{$ MIO015,LFS11:1\} \\
& $\{$ MT013, RM02:1\} \\
& $\{$ DSD002, MT013:1\} $:$ RM02:1\} \\
RM02 & $\{$ RM02, DSD002:1\} \\
& $\{$ MIO015, MT013:1\} \\
& $\{$ MT013, MIO015:1\}
\end{tabular}




$\begin{aligned} \text { PDC001 } & \{\text { LB101, PDC001:1\} } \\ & \{\text { PDC001, LB101:1\} } \\ & \{\text { DSD002, PDC001:1\} } \\ & \{\text { PDC001, DSD002:1\} } \\ & \{\text { PDC001, PFW004:1\} } \\ & \{\text { PFW004, PDC001:1\} } \\ & \{\text { LSF11, PFW004:1\} } \\ & \{\text { PWF004, LSF11:1\} }\end{aligned}$

Maka terdapat 22 subset yang layak untuk dihitung tingkat support dan confidence-nya. Setelah mendapatkan subsets yang memenuhi syarat, kemudian nilai support dan confidence dihitung. Adapun nilai minimum support adalah $2 \% \leq$ dan nilai confidence yaitu $\geq 10 \%$ untuk mengukur seberapa besar valid tidaknya aturan asosiasi tersebut.

Sebelum menghitung nilai support terlebih dahulu mengurutkan kombinasi kode produk dengan urutan frekuensi tertinggi, adapun hasilnya dapat dilihat pada Tabel dibawah ini :

Tabel 9. Frekuensi frequent pattern

\begin{tabular}{lc}
\hline \multicolumn{1}{c}{ Kombinasi Kode Produk } & Frekuensi \\
\hline LB0101, LFS11 & 1 \\
LFS11, LB0101 & 1 \\
LB90, LFS11 & 1 \\
LFS11, LB90 & 1 \\
LB0101, MIO015 & 1 \\
MIO015, LB0101 & 1 \\
LFS11, MIO015 & 1 \\
MIO015,LFS11 & 1 \\
\hline
\end{tabular}

Pada tahapan ini menentukan nilai support pada setiap itemset kombinasi kode produk dengan rumus yang sudah dijelaskan sebelumnya pada landasan terori sebagai berikut :

$$
\text { Support }(\mathrm{A}, \mathrm{B})=\mathrm{P}(\mathrm{A} \cap \mathrm{B}) \frac{\text { Jumlah Transaksi mengandung } \mathrm{A} \cap \mathrm{B}}{\text { Total Transaksi }}
$$

Adapun proses dan hasil menghitung support dari setiap kombinasi kode produk yang muncul dapat dilihat pada Tabel dibawah ini :

Tabel 10. Frekuensi Support Association Rules

\begin{tabular}{lcc}
\hline \multicolumn{1}{c}{ Kombinasi Kode Produk } & Frekuensi & Support \\
\hline LB0101, LFS11 & 1 & $2 / 24 \times 100 \%=9 \%$ \\
LFS11, LB0101 & 1 & $2 / 24 \times 100 \%=9 \%$ \\
LB90, LFS11 & 1 & $1 / 22 \times 100 \%=5 \%$ \\
LFS11, LB90 & 1 & $1 / 22 \times 100 \%=5 \%$ \\
LB0101, MIO015 & 1 & $1 / 22 \times 100 \%=5 \%$ \\
& Dan seterusnya & \\
\hline
\end{tabular}

Selanjunya menentukan nilai Confidence pada setiap itemset kombinasi kode produk dengan rumus yang sudah dijelaskan sebelumnya pada landasan teori sebagai berikut :

$$
\text { Confidence }(\mathrm{A} \rightarrow \mathrm{B})=\frac{\text { Jumlah Transaksi mengandung } \mathrm{A} \cap \mathrm{B}}{\text { Total Transaksi A }}
$$

Tabel 11. Frekuensi Confidence Association Rules

\begin{tabular}{lcc}
\hline Kombinasi Kode Produk & Frekuensi & Confidence \\
\hline LB0101, LFS11 & 1 & $2 / 6 \times 100=33 \%$ \\
LFS11, LB0101 & 1 & $2 / 6 \times 100=33 \%$ \\
LB90, LFS11 & 1 & $1 / 8 \times 100=13 \%$ \\
LFS11, LB90 & 1 & $1 / 6 \times 100=17 \%$ \\
LB0101, MIO015 & 1 & $1 / 6 \times 100=17 \%$ \\
& Dan seterusnya & \\
\hline
\end{tabular}

Berdasarkan hasil pencrian nilai support dan confidence, maka didapati hasil association rulesnya sebagai Tabel dibawah :

Tabel 12. Hasil Association Rules

\begin{tabular}{lccc}
\hline Kombinasi Kode Produk & Frekuensi & Support & Confidence \\
\hline LB0101, LFS11 & 1 & $9 \%$ & $33 \%$ \\
LFS11, LB0101 & 1 & $9 \%$ & $33 \%$ \\
LB90, LFS11 & 1 & $5 \%$ & $13 \%$
\end{tabular}


LFS11, LB90
LB0101, MIO015
1

1

$5 \%$

$5 \%$
$17 \%$

$17 \%$

\section{Dan seterusnya}

Dari tahap-tahap yang dilakukan diatas, maka aturan asosiasinya sebagai berikut :

1. Jika MTI memesan Lifebouy bw $450 \mathrm{ml}$ maka juga memesan Lifebouy shp $170 \mathrm{ml}$ hairfall dengan nilai support 9\% dan confidence $33 \%$.

2. Jika MTI memesan Lifebouy shp $170 \mathrm{ml}$ hairfall maka juga memesan Lifebouy bw $450 \mathrm{ml}$ dengan nilai support $9 \%$ dan confidence $33 \%$.

3. Jika MTI memesan Lifebouy 80gr total prtc maka juga memesan Lifebouy shp 170ml hairfall dengan nilai support $5 \%$ dan confidence $13 \%$.

4. Jika MTI memesan Lifebouy shp $170 \mathrm{ml}$ hairfall maka juga memesan Lifebouy $80 \mathrm{gr}$ total prtc dengan nilai support $5 \%$ dan confidence $17 \%$.

5. Jika MTI memesan Lifebouy bw 450ml maka juga memesan Molto aio blue 250ml dengan nilai support 5\% dan confidence $17 \%$.

Berdasarkan pada hasil perhitungan maka didapatkan beberapa barang yang direkomendasikan serta diajukan pemesanannya sesuai dengan nilai confidence (interval kepercayaan di atas $20 \%$ adalah sebagai Tabel dibawah ini :

Tabel 13. Rekomendasi Produk

\begin{tabular}{cll}
\hline NO & Nama Produk & Pemesanan \\
\hline 1 & Lifbouy bw 450ml, lifebouy shp 170ml hairfall & Bersamaan \\
2 & Molto AIO blue 250ml, Lifebouy bw 450ml & Bersamaan \\
3 & Molto AIO blue 250ml, lifebouy shp 170ml hairfall & Bersamaan \\
4 & Molto trika 450ml blu, Rinso molto ultra 800gr & Bersamaan \\
5 & Dove shp daily shne 160ml, Rinso molto ultra $800 \mathrm{gr}$ & Bersamaan \\
6 & Molto AIO blue 250ml, Molto trika 450ml & Bersamaan \\
7 & Pond's am day cream jar 25ml, Lifebouy bw 450ml & Bersamaan \\
8 & Pond's am day cream jar 25ml, Dove shp daily shne 160ml & Bersamaan \\
9 & Pond's am day cream jar 25ml, Pond's ff pure white 100g & Bersamaan \\
10 & Pond's ff pure white 100g, Lifebouy shp 170ml hairfall & Bersamaan \\
\hline
\end{tabular}

\section{KESIMPULAN}

Berdasarkan uraian pada bab-bab sebelumnya, Sehingga dapat ditarik beberapa kesimpulan, yaitu:

1. Dengan memnfaatkan proses data mining dapat mengetahui pola pemesanan produk MTI di PT. Unilever.

2. Algoritma FP-Growth dapat dilakukan untuk mengetahui pola pemesanan produk MTI pada PT. Unilever.

3. Dengan melakukan pengujian Algoritma FP-Growth pada Rapidminer, dihasilkan sebuah rule atau asosiasi berdasarkan nilai support dan confidence.

\section{REFERENCES}

[1] S. Kurniawan, W. Gata and H. Wiyana, "Analisis Algoritma FP-Growth Untuk Rekomendasi Produk Pada Data Retail Penjualan Produk Kosmetik (Studi Kasus : MT Shop Kelapa Gading)," Seminar Nasional Teknologi Informasi dan Komunikasi (SENTIKA), pp. 61-69, 2018.

[2] E. Prasetyo, Data Mining Konsep dan Aplikasi Menggunakan MATLAB, Yogyakarta: Andi, 2012.

[3] E. Prasetyo, Data Mining Mengolah Data Menjadi Informasi Menggunakan Matlab, Yogyakarta: Andi, 2014.

[4] D. Nofriansyah, Buku Algoritma Data Mining dan Pengujian, Yogyakarta: Pendidikan Deepublish, 2017.

[5] A. Preantoko, Jago Microsoft Excel 2010, Jakarta: Kawan Pustaka, 2010. 